\title{
Health Maintaining and Disease Curative Ethno-medicinal and Religious Practices by the Santals of Keonjhar District, Orissa
}

\author{
Prof. Falguni Chakrabarty ${ }^{1}$, Amit Kumar Kisku ${ }^{2}$ and Mohan Chandra Dolai ${ }^{3}$ \\ ${ }^{1}$ Department of Anthropology, Vidyasagar University, Medinipur, West Bengal, 721102, \\ ${ }^{2}$ Lecturers, Department of Anthropology, Vidyasagar University, Medinipur, West Bengal, 721102, \\ ${ }^{3}$ Research Scholars, Department of Anthropology, Vidyasagar University, Medinipur, West Bengal, 721102,
}

\begin{abstract}
Ethno-medicine is a sub-field of medical anthropology and deals with the cultural interpretations of health, disease and illness and also addresses the health care seeking process and healing. The knowledge and use of medicinal plant species by the traditional healers as well as by the community members was investigated in a Santal village of Orissa. On the basis of the ethnographic fieldwork with the help of standard anthropological methods it has been revealed that although the Santal's concept of disease and treatment is centered on religious beliefs and practices but they are regularly dependent on herbal medicines along with modern allopathic treatment. The present paper is an attempt to explore the repository of herbal medicines used by the Santals of a particular village of Orissa. The paper also attempts to explore the source and method of collection of the medicinal plants by the villagers from their surrounding environment.
\end{abstract}

Key words: Traditional Medicine, Ethno-medicine, Santals, Religious practices

\section{Introduction}

World Health Organization(WHO) defines Traditional Medicine as "the health practices, approaches, knowledge and beliefs incorporating plant, animal and mineral based medicines, spiritual therapies, manual techniques and exercises, applied singularly or in combination to treat, diagnose and prevent illnesses or maintain well-being".Countries in Africa, Asia and Latin America use traditional medicine to help meet some of their primary health care needs, as for example, in Africa, up to $80 \%$ of the population uses traditional medicine for primary health care. WHO, however, also notes that its use is spreading in popularity in industrialized countries. For example, in the United States, 158 million adults use complementary medicine (a field which incorporates traditional medicine but is broader in scope).

WHO also notes, that "inappropriate use of traditional medicines or practices can have negative or dangerous effects" and that "further research is needed to ascertain the efficacy and safety" of several of the practices and medicinal plants used by traditional medicine systems. Core disciplines which study traditional medicine include ethno-medicine, ethno-botany, and medical anthropology.

The ethno-medicinal system or traditional medicine has two universal categories of disease etiologynatural and un-natural (supernatural) causes. Natural illness explains illness in impersonal systematic terms. Thus, disease is thought to stem from natural forces or conditions such as cold, heat and possibly by an imbalance in the basic bodily elements. Un-natural illness is caused by two major types of supernatural forces. Occult causes which are the result of the evil spirits or human agents using sorcery and spiritual causes which are the results of penalties incurred for sins, breaking taboos or caused by God. In the scientific arena, ethnomedical studies are generally characterized by a strong anthropological approach, more than a bio-medical one. The focus of these studies is then the perception and context of use of traditional medicines, and not their bioevaluation. Ethno medicine refers to the study of traditional medical practice. It can encompass methods of diagnosis and treatment. In some cases it is associated with professional medicine men and women, in others with lay persons who have acquired knowledge from parents or relatives.

Herbalism is a traditional medicinal or folk medicine practice based on the use of plants and plant extracts. Herbalism is also known as botanical medicine, medicinal botany' medical herbalism, herbal medicine, herbology, botanical medicine and phytotherapy. Sometimes the scope of herbal medicine is extended to include fungi and bee products, as well as minerals, shells and certain animal parts. Many plants synthesize substances that are useful to the maintenance of health in humans and other animals. These include aromatic substances, most of which are phenols or their oxygen-substituted derivatives such as tannins. Many are secondary metabolites, of which at least 12,000 have been isolated a number estimated to be less than $10 \%$ of the total. In many cases, these substances (particularly the alkaloids) serve as plant defense mechanisms against predation by microorganisms, insects, and herbivores. Many of the herbs and spices used by humans to season food yield useful medicinal compounds. With only a few exceptions, most herbal treatments have not been tested for safety and efficacy utilizing scientific studies or clinical trials. The scientific and medical communities state that herbal treatments may be risk the well-being or life of the patient when used in lieu of standard medical treatments. 


\section{Health Maintaining and Disease Curative Ethnomedicinal and}

Religious Practices by the Santals of Keonjhar District, Orissa

Ethno medicine is a sub-field of medical anthropology and deal with the study of traditional medicines, not only those that have relevant written sources (e.g. Traditional Chinese medicine-Ayurveda) but especially those knowledge and practices which have been orally transmitted over the centuries. The term traditional medicine describes medical knowledge systems, which developed over centuries within various societies before the era of modern medicine; traditional medicines include practices such as herbal medicine, Ayurvedic medicine, Unani medicine, acupuncture, traditional Chinese medicine, traditional Ayurvedic medicine, South African Muti, Yoruba Ifá, as well as other medical knowledge and practices all over the globe. In the scientific area no ethno medical studies are generally characterized by a strong anthropological approach more than bio-medical one. The focus of these studies is the perception and contest of use of traditional medicines and not their bioevolution.

In India, the people, especially the tribals, living in forest or its adjoining areas, since long past, maintaining their health with the help of their ethno-medicinal knowledge. One such tribe of eastern India whose tradition of ethno-medicine practices is the Santals.

The Santals are the $3^{\text {rd }}$ largest tribes of India, spread over a wide area in Bihar, Orissa and West Bengal. Some of them also migrated to Tripura, Assam and Bangladesh as plantation laborers in tea garden.

They are racially Proto-Australoid (Guha, 1944) and linguistically belong to the Mundari group of AustroAsiatic sub-family (Grierson, 1911). Other than Santali or Har Raur, they also speak the language of the region where they live. Recently they have introduced their own script known as Olchiki (Das and Basu, 1982).

The Santals primarily eke out their living from agriculture. However, where they live within or very close to the forest, a significant amount of their cash income is earned by way of selling of Non-Timber Forest Produces (NTFP). In the recent years, with the intrusion of heavy and ancillary industries, many of them have switched to the secondary sector. Very few of them are found to be engaged in the white collar jobs (Das and Basu, 1982). With the emergence of multi-cropping of paddy and different cash-crops, a large number of them are found to work as seasonal migrant laborers.

The Santals are an exogamous clan based group. The clans are regarded as equal to another clan and there is no class distinction either in status or occupation. Thus, their society is characterized by democratic equality.

The Santals have their own religion replete with the notion of supreme God Marangburu tutalory deity and a number of other subsidiary deities and spiritual forces -- both benevolent and malevolent. Many of these deities are linked to natural elements like trees, animals, forests, stones, hills, water, stream, river etc. Sometimes they are also found to adopt the Hindu Gods and Goddesses. A large section of them claim that they have separate religion which they call Sari-dharam.

\section{Objectives And Methodology Of The Present Work}

A number of publications on ethno-medicinal practices prevalent among the tribal communities of India are available. The authors whose name deserves special mention in this context are namely: Bodding 1925, Fuchs1964, Jaggi1973, and Jain1981etc. However, these authors while dealing with the ethno-medicinal practices and / or knowledge of a tribal community only considered the community as a whole but not specifying their particular habitat. Even P. O. Bodding who may be considered a pioneer researcher on the Santal medicine gave a general account of the said community without mentioning any particular locality that was under consideration of his study. In his famous study under the title "Studies in Santal medicine \& connected folklore" Bodding only mentioned about the historical habitat of the Santals but not of a particular locality.

In the above background the present work deals with the ethno medicinal practices of the Santal tribe living in a particular village named Sonatangri located under the Ghasipura police station of Anandapur subdivision in the Keonjhar district of Orissa, India. The total number of Santal population in the village is 393(212 male \& 181 female) who are distributed over 69 households. Standard anthropological methods and techniques like household census survey, participation observation, case history, questionnaire and genealogical method was followed to obtain the necessary information. Although Sonatangri village is multiethnic in nature but it is predominated by Santal community. Thus, we find that there are 53 Santal households, 11 Munda households and 5 Lohar households who belong to Hindu caste and who are primarily Blacksmith by occupation.

\section{Rituals and religious activities related to forest Resource collection}

The Santals of Sonatangri worship the Gods and goddesses mostly associated with the hills and forests. They maintain a sacred grove (termed as Jaher), which they consider as the abode of their gods and goddesses. Their traditional village council is centered on their sacred grove. The Santals of Sonatangri organise festivals of new flower (Baha) every year on the full moon day in the month of Fagun. Prior to the Baha they abstain from collecting forest resources (especially tender leaves) for fifteen days. 


\section{Ethno-Medicinal Practices}

The Santals of Sonatangri are not only quite aware about the modern medicine but they also frequently visit the nearby primary health centre and sub-divisional hospital respectively located 3 and $6 \mathrm{~km}$. away from their village. However, owing to their virtual habitat in a hill forest environment some of them have developed expertise of treatment with the help of herbal medicine. In fact, it is observed by the present researchers during their field work that there are at least four Santal elderly people living in Sonatangri who very often treat their co-villagers with the help of herbal medicine. Not only all the males and females of the village are more or less aware of the ethno medicinal practices but the children of the village are also not far behind them regarding the knowledge about the medicinal plants and their uses. In the following section a brief description of the diseases, symptoms and treatment as found among the Santals of Sonatangri has been presented.

\section{Chadrak/ Baldness}

Symptoms: - This may attack adults. The hair falls off entirely.

Medicine: - Munga chal, the bark of Moringa pterygosperma

Process of use- It is grinded and smeared on head daily.

\section{Bohok haso/Headache}

Medicine: - 1) Ghni Kumari sakam ros, the leaves juice of Aloe indica

Process of use - Smeared on the forehead daily.

2) Nim sakam, the leaf of Melia azaclirachta.

Process of use-This leaf is smashed with water and wraped in a piece of cloth, squeeze on the head.

3) Dundu Ket Jo, the fruit of Gardinia turgida.

Process of use-Grind it and apply to the head.

\section{Mendak/Opthalmia, generally conjunctivitis}

Symtoms: - There is a considerable pain with a gritty feeling in the eyes night and day, and a quantity of matter is discharged. It generally commences in this way when rain first falls people wash their face in muddy water on bath in the same; then they get this disease.

Medicine: - Pusi toa lore, resin of Euphobia pilulifera.

Process of use - Dropped into the eyes.

\section{Andhua or Rat Kana / Night blindness}

Symptoms: - People are unable to see at all at night, but in the day time can do so perfectly well.

Medicine: - $\quad$ 1) Nanha dudhi lota rehet, the roots of Ichnocarpus frutescens.

Process of use - It is grinded fine, wrap in cloth, squeeze and drop the liquid into the eyes.

2) Terel jer, the resin of Diospyros tomentosa. Kahu pit, the bile of crow.

Process of use - These are mixed and given to drink for 7 days.

\section{Pali rua/Inter mittent fever (Malaria)}

Symptoms: - In this the fever is not in evidence every day. But returns after an interval of one day or it may be two.

Medicine: - 1) Saparom sakam, the leaves of Nyctanthes arbortristis.

Process of use -This is boiled and gives to drink daily.

2) Tandi catom sakam, the leaf of Desmodium friflorum.

Process of use - It is boiled with water, given to drink.

\section{Lach haso/ pain in stomach}

Medicine: - $\quad$ 1) Saoraj Jan, the seed of vernonia anthelmitica

Process of use - Grinded and mixed with water and given to eat.

2) Patal garu rehet the roots of Rauwolfia serpentine.

Process of use - It is smashed and given to eat.

3) Hat rehet, root of Holarrhena antidysenterica.

Process of use - Smashed with water and given to eat in empty stomach.

\section{Hawa duk se meram lach odok/cholera}

Medicine: - 1) Motam ut, a certain edible mushroom. 
Process of use - It is smashed with water and gives to eat.

2) Sengel sin-rehet, the root of Tragia involuerata.

Process of use - Smashed and given to eat.

\section{Allergy}

Medicine: - $\quad$ 1) Matkom lore, resin of Bassia latifolia.

2) Poso lore, resin of Tetranthera monopetala

3) Kerosene oil.

Process of use - Mixed in equal quantities all of these and anointed.

\section{Punra dad}

Symtoms: - $\quad$ It is one type of skin disease

Medicine: - Baru sakam, the leaves of carthamus tinctorius.

Process of use - Smashed and smeared on affected area for 7 consecutive Sundays.

10. Koram haso/Pain in the chest

Medicine: - $\quad$ 1) Rohin chal, the bark of Soymida febrifuga. Khayer chal, the bark of Acacia catechu,

Process of use - Grinded and given some to drink for 3 days and sometime smeared on the chest.

2) Bagpiper foreign liquor mixed with Rohin chal and gives to drink.

\section{Get-khal-len-khan/Wounds caused by iron implements}

Medicine: - 1) Sega rehet, roots of Mimosa rubicaulis.

Process of use - Grinded and smear on the affected portion.

2) Bir kannda sakam, leaf of Mukia sp.

Process of use - Grinded and smear on affected portion. It helps to prevent from septic.

\section{Ti janga Machkao}

Medicine: - $\quad$ Tarop chal, bark of Buchanania latifolia. Sugei ketouda, tuber of Modhuca indica.

Process of use - Grinded and smeared on affected portion.

\section{Laodokok/diarrhea}

Medicine: - $\quad$ 1) Ambra chal, bark of sponsdias mangifera.

Ul chal, bark of Mangifera Indica.

Kumbirchal, bark of careya arborea.

Sodare chal, the bark of Polythia asuberos.

Process of use - Grinded these together then boil with water and give to eat.

2) Pisri dog Jan, fruit of Psidium guyava.

Process of use - Grinded with water and give to eat

14. Laora ghao

Medicine: - $\quad$ Rol rehet, root of Terminalia chebula

Lopon rehet, root of Terminalia bellerica

Meral rehet, roots of Phyllanthus emblica.

Kahu Botke rehet, root of Bryonia lasinosa.

Process of use - Grinded these together and give to eat.

\section{Khog /cough}

Medicine: - Mansaku rehet, root of Alocasia indica.

Process of use - It is friend in ghee and given to eat in empty stomach 2-3 days.

\section{Katic gidrako mandak/cold of children}

Medicine: - $\quad$ Tursi sakam ros, juice of the Ocimum sanctum

Kalia jira, Nigella indica.

Adhe ros, Zingiber officinalis.

Nele rose, Honey.

Process of use - These mixed with honey and given to drink babies 2-3 days only. 
17. Hamus/Anaemia

Symptoms: - When one has suffered a long time from spleen, the blood in the body dries up causing the body to become pale.

Medicine: - Saparom rehet, the root of Nyctanthes arbortristis.

Process of use - Grinded with water and given to drink.

18. Dorod( Harmo Haso)/ Pain in any part of the body

Medicine: - Halim Jan ros, the juice of seed of Lepidium sativum.

Process of use - Grinded fine and rubbed patient.

19. Jari phulauk/ Ulcerated tongue.

Symptoms: - In this sores appear on the tongue of both children and adults.

Medicine: - $\quad$ Bar chal the bark of Mimusops elengi.

Process of use - It is boiled in water let him wash the mouth out with that water until recovery, no salt to be eaten for three days.

20. Mocha ghao/Sores in the mouth

Medicine: - $\quad$ Nanha dudhilota rehet, the root of Ichnocarpus frutescens,

Kujri rehet, the root of Celastrus paniculard.

Process of use - Grind these together, cook in mustard oil and apply to the affected part.

21. Tarpa

Medicine: - Baru sunum, Oil of Schleiehera trijuga.

Process of use - Anoint in whole body.

22. Hormo vagi doho/Maintains a well health

Medicine: - $\quad$ Bare dare rehet, root of Ficas bengalensis.

Tale dare rehet, root of Borassus flabilifer.

Process of use - Grinded and to be mix it with water. Its daily consumption maintains a well health.

\section{Lutur ghao/Ear- sore}

Medicine: - 1) Urine of Sus sp.

Process of use - It is given as drop into the ear.

2) Bone dist of Tiger Panthera Tigris.

Process of use - It is given into the ear.

\section{Lutur bili}

Medicine: - $\quad$ 1) Bir Kundri sukum ros, the juice of leaf of Zehneria Umbellata.

Process of use - It is given as a drop into the ear.

2) Blood of chutia baduri, pteropus sp.

Process of use - Drop into the ear.

3) Gandi sukum ros. The juice of leaf of Tagetes erecta.

Process of use - It is evated and applies into the ear.

25. Piles

Medicine: - Head of Tortoise Trionyx sp.

Process of use - Burning head or raw head is grinded and given to eat with water.

\section{Reyar Lagho/Feeling cold}

Medicine: Baru sunum, oil of Carthamus tinctorius.

Process of use - It is anointed in the whole body.

\section{Kausa/ Sores}

Medicine: - Nim sukum, leaf of Melia araclirachta.

Nim chal, bark of Melia araclirachta.

Process of use - These are boiled with water and anoint on the affected portion. Besides the nim sunum (neem oil) are also used. 


\section{Jan rapudok/Fractured bones}

Medicine: - $\quad$ Bod Lar rehet, the root of Vitis adanta

Had jora naritet, the tendrils of Cissus quadrangularis.

Process of use - Grind, apply as a plaster and affix splints.

\section{Ti janga se jan bhitri haso/Pain in limbor bones}

Medicine: - Bonkapsi da, the bulls of Thespesia Lampas.

Kadar rehet, the root of Asparagus racemosus.

Bizr campa rehet, the root of Ochna squarrosa.

Process of use - Grind with water and after squeezing the water out give about eight ounces of

30. Bat/gout it to drink for three or four days.

Medicine: - 1) Poso chal, the bark of Teramthera monopetala.

Process of use- Extracting resin from this bark, rubs on the body.

2) Paora ic. The excrement of Columba livia.

Process of use - Grind and anoint the affected portion.

3)Chini, sugar.

Process of use - It is boiled with water and applies to the patient.

\section{Lo ghao/Burns}

Medicine: - $\quad$ 1) Merom itil reak sunum, oil made from goat's fat, apply this.

2) Dhuna, resin of Shorea robusta

3) Utin sunum mustered oil

Process of use - Mix these into an ointment and apply once a day, healing will follow.

\section{Gidra aahao / evil eye on children}

Symptoms: - This is a spell cast generally on children, but sometimes also on adults. After it children cry, sometimes vomit, and after that have watery evacuations.

Medicine:- The spine of Naza sp., spine of sakun , the spine of timi, are tied within amulet to baby's waist .

\section{Up nuruk/ Hair falls of women}

Medicine: - Kagji nimbu ros, the juice of fruit of citrus acida.

Process of use - Heated juice applies to the hair; as a result hair root is strong.

\section{Sidka lai/Pain in means time}

Medicine: - Halim Jan, the seed of Lapidium satitum.

Process of use - Smashed and heated with cow milk and given to eat.

\section{Khok manda/Cough and cold}

Medicine: - $\quad$ 1. Rasun, Garlic

Adagathia ghas da, the bulb of Panicum repens

Bulun, Salt

Process of use - Grind these together, make into pills to be taken daily. And cold will certainly get well.

2. Soso Semacarpus cuneifolia

Process of use - Grind with roasted rice and let the patient eat it.

\section{Dad/Ringworm}

Medicine: - Dunduket rehet, the root of Gardinia turgida.

Process of use - Grind these together, stir in utin sunup, mustard oil and let him anoint him there with

\section{Gorob horko tan rualenre/continuous fever during pregnancy}

Medicine: - Nim sakam, the leaves of Melia azadirachta 
Health Maintaining and Disease Curative Ethnomedicinal and

Religious Practices by the Santals of Keonjhar District, Orissa

Process of use - to be boiled, the water to be drained of and then with the addition of mahut gur, molasses refuse, to be drunk like tea. All the symptoms will disappear and no harm ensues.

38. Toa anjedok/The drying up of milk

Symptoms: - Sometimes women's milk does not flow after giving birth to a child; sometimes the same happens in fever or something similar

Medicine: - 1) Pusi toa rehet, the root of Euphorbia pilulifera.

Process of use - Root up the entire plant and grind it small strain off the water and let the patient. Drink itmixed with sugar or sugar candy, which will cause the

39. Up hende ocoe/To darken grey hair milk to flow.

Medicine: - Bana ic bears' excrement

Mithi, Trigonella Foenum Graecum.

Process of use - Mix and grind these together and rub the mixture into the head on three Sundays, and the hair will become black grain.

N.B- this only applicable for young people prematurely grays, not for old people.

40) Toa jorote lutur bele/Ear suppuration from the entry of milk

This arises from the carelessness of the mother which suckling the baby, some suckle while lying down and the milk dripping into the ear causes the mischief.

Medicine: - Ato kundi rehet, the root of a cultivated Zehneria Umbellata.

41. Luturhaso/ Ear aches

Process of use - Grind and without cooking pours into the ear.

Medicine: - Tale dar, a leaf, stem of Borassus flabelliformis.

Process of use - Pound and fry and drop into the ear.

42. Tan rua/Continuous fever

Symptoms: - If one walks about or works in the sun the limbs ache, the lower exmrities or benumbed and locomotion unsteady, the body feels weak and tired and the urine is highly coloured.

Medicine: - $\quad$ 1. Lopon chal, the bark of Terminalia bellerica.

Mahut gur, molasses refuse.

Process of use - Take the juice of the former, mixed it with the latter and makes the patient drink it, and he will certainly get well.

2. Tarop chal ros, the juice of the bark of Buchanania latifolia

Process of use - The patient to drink this for about five days and the aching of the limbs will cease.

43. Uchlau/Vomiting

Medicine: Utki rehet, Tursi sukam, the leaves of Ocimum sanctum.

Process of use - Grind together and give to drink.

44. Lach haso/Stomach- ache

Medicine: - Hat rehet, jan, jo, se, chal, the roots, seed, fruit or bark of Holarrhena antidysentrica .

Process of use - Grinded and given to drink.

Medicine: - Kalmeg, the leaves of Andrographis peniculata.

Process of use - Grinded and given to drink.

45. T.B. namre/Tuberculosis

Symptoms- $\quad$ Prolonged cough and fever.

Medicine: - Nim sakum, the leaf of Melia azadirachta

Process of use - Paste of mature and green leaf along with hot juice of the boil rice is offered to the patient regularly.

46. Basonta/ Chickenpox

Symptoms: - Fever, and blisters over the skin of the body

Medicine: - $\quad$ 1) Jara chal , the bark of Jatrophe sp.

Process of use - The patient is fed with juice of this bark along with husked rice.

Medicine: - 2) Nim sakam, leaf of Melia azadirachta.

Process of use - The paste of green neem leaf and turmeric is smeared on the body of the patient.

The patient's bed is covered with dry neem leaf and patient sleep on it.

Sometime patient body is washed with the water of green coconut. 
47. Swelling of gum Medicine: -

\section{Bis junre/Consumption of poison}

1) Twigs of Totka jada tree used as tooth brush by the patient.

2) The gum of totka jada tree and fried hot salt is taken in a piece of cloth and foment applied in swelled gum

Medicine: - The patient is fed with raw egg or solution of cow dung which causes vomiting. So that poisoning come out from the abdomen of the patient.

\section{Dan vut lagaore/Possessed by the evil spirit}

Symptoms: - Pain in body and high fever of the patient.

Medicine: - The patient fed with the paste made from the root of gaud tree.

Process of use - A portion of the said paste is also smeared on the head of the patient.

50. Bale Gidrako Jhara/ Stomach upset of the baby

Medicine: - The patient is fed with juice made from root of ghora boch plant.

\section{Roga hormo/ Thinness of the baby}

Medicine: - The fruit of petraoler tree is tied on the waist of the baby.

\section{Bale gidrako uchlau/Infants vomiting}

Medicine: - A chain made with the fruits of Chti jada tree is prepared and it is worn of the body.

\section{Sanam lekan bin ger bis ra/ Antidotes for the poison of all kind of snakebite}

Medicine: - $\quad$ 1. Kumbir chal, the bark of Careya arborea.

Process of use - Grinded and given to drink and anointed there with.

2. Seed of Tamarind tree is made in two pieces and the exposed

Process of use - Flesh of the seed is placed on the spot of the bite.

3. Some time, the spot of the bite is rubbed with a piece of earthenware.

\section{Vetenary medicine}

The Santals of Sonatangri also treat their domestic animals (cow\& goat) with the help of some indigenous medicine, which they prepare out of the variety of plants collected from the nearby forest. Here is a list of some veterinary diseases and their treatment as found among the Santals of Sonatangri has been presented.

1) Mouth swelling of the cows

Medicine:- Mixture of matured tamarind flesh, salt and soot is poured on the mouth of the cow.

2) Infection of cow hoof

Medicine:- A paste made from the seed of Kusum tree is applied of affected spot.

3) Lose motion of goat

Medicine:- The goat is fed with mixture prepared with the leaf of Nagarjun tree, molasses , fermentedfroth of boiled rice.

4) Scar on the body of goat

Medicine:- The spot is smeared with the ointment made from sugar, salt and coconut oil.

5) Breaking of cow horn

Medicine:- The seed of Soso tree along with khari mati and women hair is packed together on a cloth and tied on the broken horn of the cow.

6) Fracture of the leg of the cattle

Medicine: - A paste is prepared from the root of Hat jare and after heating the same. It is applied on the fracture leg. At the same time a stick made of bamboo is tied vertically with the fractured leg.

7) Lip sore of goat month

Medicine; - A particular variety of stone (gamchha dhiri) is rubbed on the lip of the goat which removes the dried skin.

8) Entrapments of the abdomen of the cow

Medicine: - The women hair coming out of combing is roosted and taken closer to the nose of the cow.

9) Sore in the tongue of the cattle

Medicine: - The cow is fed with the leaf of Kari jai and bamboo tree at the sometime

10) Reduction of the lactation of the cow

Medicine: - The cow is fed with the root of Janum are tree boiled in rice.

11) Pilhoi, Anthrax

Medicine:- Kedar rehet (the root of Bonnaya veronicaefolia), Rasun (garlic), Meral chal ( the bark of Phyllanthus emblica) 
Process of use- Grind and mix these and make to drink.

12) Gai kada raput lenre/ Bone fractures of the cattle

Medicine:-1)Suruj mukhi, Helianthus annus.

2) Catom arak, Marsilia quadrifolia.

Process of use- Grinded together, applied thickly as a plaster and affix splints.

13) Gai kada jaha then hasokore/ Pain of the cattle anywhere in their body

Medicine: - Rub them with kerosene oil and bath with hot water.

\section{Frequency and method of use of different flora}

The present study revealed that the Santal people were used 78 medicinal plants for the treatment of 53 human ailments. The 78 medicinal plants belonging into 35 families were used by the Santals. The Meliaceae family provided the largest number of species ( 6 species), followed respectively by the Apocynaceae \& Anacardiaceae (5 species each), Euphorbiaceae and Fabaceae (4 species each), Asteraceae, Sapotaceae, Combretaceae and Cucurbitaceae (3 species each), Laminaceae, Liliaceae, Rubiaceae, Olecaceae, Brasicaseae and Arecaseae ( 2 species each) and the rest families were represented by one plant in each family. We document that several parts of individual plant e.g., root; bark, leaf, resin, fruit, seed, tuber, bulb, stem etc. are used as medicine. For curing the ailments, the use of aboveground plant parts was

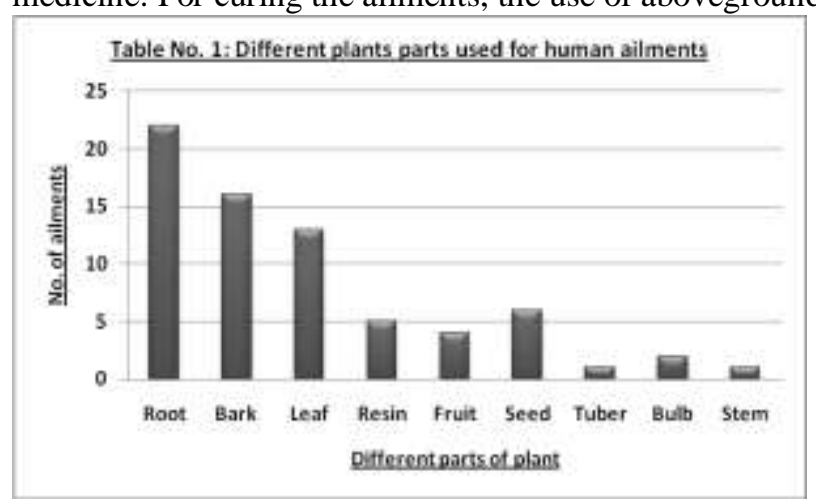

higher $(65.71 \%)$ than the underground plant part that is $34.29 \%$. Of these 70 uses of various plant parts obtained in the present study, use of roots comprised the major mode of use $(31.43 \%)$, followed by bark $(22.86 \%)$, leaf $(18.57 \%)$, seed $(8.57 \%)$. In only one ailment (drying up of women's milk), the whole plant (euphorbia pilulifera) were used as medicine. Medicinal plant parts were reported mostly to be grinded $(47.54 \%)$, smashed $(11.48 \%)$, smeared and mixed (9.84\% each), boiled $(8.19 \%)$ during preparation of remedies. It was observed that most of the preparations include the combination of two or more species $(52.83 \%)$ and

$47.17 \%$ single plant species are used. External applications as well as internal consumption are involved in the treatment of disease. Analysis of the species level data discovered the oral $(47.44 \%)$, external application

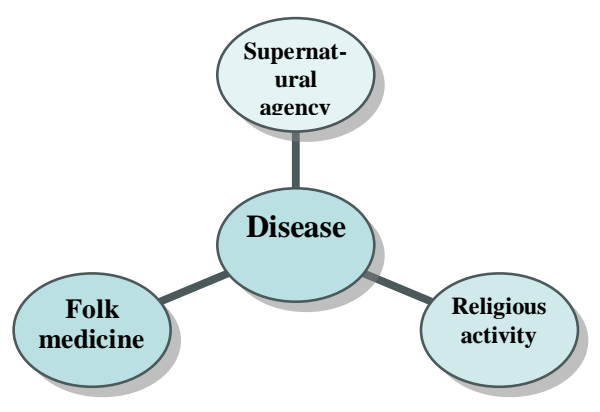
$(35.9 \%)$,
and ear
$(8.97 \%)$ as
major
administra
tion route
of ethno-
medicine
used. A
single

Table No. 2: Methods of preparation of traditional medicine

\begin{tabular}{|c|c|c|}
\hline Methods & $\begin{array}{l}\text { No. of } \\
\text { plant }\end{array}$ & $\begin{array}{l}\text { Percentage } \\
(\%)\end{array}$ \\
\hline Grind & 29 & 47.54 \\
\hline Smashed & 7 & 11.48 \\
\hline Smeared & 6 & 9.84 \\
\hline $\begin{array}{l}\text { Mixed with } \\
\text { water }\end{array}$ & 6 & 9.84 \\
\hline Boiled & 5 & 8.19 \\
\hline Drop & 4 & 6.55 \\
\hline Fried & 2 & 3.28 \\
\hline Powder & 2 & 3.28 \\
\hline Total & 61 & 100 \\
\hline
\end{tabular}

treat a single or multiple ailments. For instance bark of Moringa pterygosperma was used to treat baldness. On the other hand, leaf and bark of Melia azadirachta was used for treatment of diverse ailments like tuberculosis, chickenpox, headache and fever during pregnancy. Remedies were generally prepared using oil, alcohol, kerosene, salt, and various animal parts etc. with different plant parts. In this study we identified eight animal species (Panthera tigris, Trionyx sp., Columba livia, Naza naza etc.), which are being used for 6 medicinal purpose like ear-sore, piles, gout, consumption of poison, evil eye on children etc. These animals are used as whole or body parts or by product like egg. Highest number of plant species ( 9 species) were used for the treatment of cough and cold related disorders, 8 species were used for healing stomach related problems and 4 species used to treat cuts and wounds. The villagers also treat 13 diseases of domestic animals (cow\& goat) with the help of 11 medicinal plants collected from the nearby forest. 


\section{Health Maintaining and Disease Curative Ethnomedicinal and}

Religious Practices by the Santals of Keonjhar District, Orissa

\section{Ritual Associated With Disease And Treatment}

Folk medicines are associated with rituals and beliefs. This is naturally done by the ojha or medicineman. Besides, using herbal medicines the Santals try to cure disease through magico-religious beliefs and practices. This study also revealed that the Santals of Sonatangri believe supernatural forces for disease causation and seek remedies through magico-religious practices. 'Evil eye' is considered to be a cause for certain ailments particularly in children. They offer prayers and sacrifices as per direction of the medicine man to appease the supernatural power believed to be responsible for the disease. A ritual call Bhujni Batiyani is practiced by the Santals of Sonatangri for well being of the villagers. They believe that by observing this ritual they will be able to protect and keep themselves away from the effect of all epidemic diseases. Bhujni, also known as 'Jugni' among the Santals of West Bengal, is a malevolent female deity existing in the Santal pantheon where, 'Batiyani' means 'leaving apart'. Thus the ritual 'Bhujui Batiyani' stands as leaving apart Bhujni from the village. This ritual generally takes place in the month of April which according to Santal almanac is known as 'Chait Bonga. But the day and date of the observation of the ritual is not fixed. For this purpose, on the penultimate night of the day of the ritual, the unmarried boys of the village assemble at the residence of the majhi (traditional village headman of the Santal). And on that night respective Santal household of the village collect their used and rejected brooms, baskets etc, and keep them in front of their respective houses. In the early morning of the next day, the unmarried Santal boys of the village collect all these dumped materials from every household and tie those materials in carrying pole. Thereafter, the boys carry those materials along with a chicken and enter in to the nearby forest. Throughout the day, they collect different medicinal plants, roots, fruits etc. from the forest. For the entire day time they spend in the forest and it is prohibitory for them to enter even within the boundary of their village. In the forest, they allow the chicken to be free with the belief that it will carry all the disease from the village and transport them to the forest.

After spending a whole day outside the village boundary they return in the evening. However, before entering in to the village boundary they sacrifice three chickens and dedicate them respectively to the Marang Buru, Jaher Aayo and Moreko Turuiko (God and Goddesses of the Santals).After the episode of sacrifices is over, they go straight to the residence of 'majhi'. In the premises of the majhi they grind all the collected medicinal plants, flowers, fruits; roots etc together and make a dry mixture out of those grounded materials. Thereafter, they distribute the portion of the mixture to all the Santal household of the village. The parts of the various medicinal plants they collected from the forest are namely: the flower or baha of Bhiru; the root or rehet of Babla ie. Acacia catechu;Urup kutur rehet, the root of Guhiri; the root of Iter, Dundu ket or Gardinia turgida, Poso orf Tetranthera monopetala, Hat or Cisus quadrangularis.

\section{Conclusion}

Basically, this research is exploratory in nature wherein a modest attempt has been made to collect some baseline empirical information regarding the manifold strategies adopted by the Santal tribe in the context of easy access to hill-forest environment in the state of Orissa in India. In fact, the very nature of the preindustrial level of technology and the character of the forest clad terrain have virtually encouraged the researchers to look into the unique processes of socio-cultural adaptation which pervades almost every sphere of the life of the Santal in the village under study.

It is revealed from the field work that apart from a very few types of ingredients which are bought from the markets and which are spotted by their foreign names, most of the stuffs used by the Santal medicine men of Sonatangri are as such procured from their own village or from the adjacent forest. It is observed that the genuine Santal remedies do not consist of a large number of ingredients. They have in each case one or two that is considered to be the essential ones.

While dealing with the ethno medicinal aspects of the Santals of Sonatangri the present researchers noticed that the crux of tribal cure complex is its mysterical ritual character that influences tremendously the pre-industrial tribal logic.

It appears from the preceding discussions that the Santals of Sonatangri perceive illness and disease as something unnatural, and make their own deductions from this proposition. They have an idea, perhaps never well defined, found out more deduction than from any direct statement, that a human being has a natural right to health and life. Disease is something foreign and inimical to man.

The Santal of Sonatangri acknowledges natural causes of illness however; they also perceive the material nature of a disease. But there is always a suspicion that the natural cause is not original one, but that evil influences are at work in the first instances.

The Santal rationality behind selecting different types and portion of medicinal plants, the role of village council in the management and distribution of the herbal medicine - all work in union to ensure not only the biological survival of this community but also its socio-cultural existence. 


\section{Acknowledgement}

We are grateful to the Santal people living in this study area. The way they co-operated me during our interaction with them is ever memorable. We are thankful to University Grants Commission (UGC) for providing financial assistance to the Research Scholar (Mohan Chandra Dolai) in his research work. We also like to convey our thanks to the Editorial Board of the Journal of Humanities and Social Science, International Organization of Science Research for accepted this research work for publication.

\section{References}

[1] Bodding, P.O.1925. Studies in Santal medicine and connected folklore: the Santal and disease. Memoirs of the Royal Asiatic Society of Bengal. 3: 427-502.

[2] ------ 1927. Studies in Santal medicine and connected folklore: Santal medicine. Memories of the Royal Asiatic Society of Bengal. 10: 133 -326.

[3] - - 1940. Studies in Santal medicine and connected folklore: How Santals live. Memoirs of the Royal Asiatic Society of Bengal. 10: 427-502.

[4] Culshaw, W.J. 1949. The Tribal Heritage. London: Luther-Worth Press.

[5] Das, A.K.and Basu, S.K. 1982. "An overview of the Santals: their past, present and future", in To be With the Santals, ed. U.K. Roy, A.K. Das and S.K. Basu, pp. 3-32. Kolkata: Cultural Research Institute, Govt. of West Bengal.

[6] Foster G. 1976. Disease etiologies in non Western medical system. American Anthropologist:78:775-82

[7] Grierson. 1927. Linguistic Survey of India. Vol. 1, Part - I Calcutta: Government of India Press.

[8] Guha, B.S. 1944. Racial Elements in thePopulation. Bombay: Oxford University Press.

[9] Orans, M. 1965. The Santal: a tribe in search of great tradition. Detroit, USA: Wayne State University Press.

[10] Skrefsurd, L.O. 1887. Horkoren Mare Hapramko Reak Katha (in Santali). Oslo.

[11] Troisi, J. 1978. Tribal Religion: Religion and Practice among the Santhals. New Delhi: Manohar Publishers. 